TecnoHumanismo. Revista Científica

Diciembre 2021 - Febrero 2022

Volumen 1 / No.4

ISSN: $2710-2394$

pp. $52-78$

https://doi.org/10.53673/th.v2i2.103

https://tecnohumanismo.online

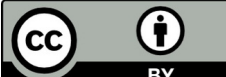

\title{
El derecho al plazo razonable en el procedimiento contencioso tributario
}

\author{
The right to a reasonable term in the contentious tax procedure \\ O direito a um prazo razoável no processo tributário contencioso
}

\section{ARTÍCULO GENERAL}

\author{
Julio César Fernández Moncada \\ Juliofernandezmoncada@gmail.com \\ https://orcid.org/0000-0002-8740-7692 \\ Investigador Independiente, Lima - Perú
}

\author{
John Hitler Mena Dávila \\ jmenad@pucp.edu.pe \\ https://orcid.org/0000-0002-3632-6550 \\ Investigador Independiente, Lima - Perú
}

Recibido 07 de Junio 2021 | Arbitrado y aceptado 25 de Agosto 2021 | Publicado en 04 Diciembre 2021

\section{RESUMEN}

En el presente artículo los investigadores pretenden analizar la jurisprudencia del Tribunal Constitucional y la Corte Suprema de la República en relación al derecho al plazo razonable y la consecuencia jurídica al evidenciarse la afectación de dicho derecho frente al derecho de propiedad de los contribuyentes; así como, la razonabilidad de los intereses moratorios durante el tiempo en exceso que se tomó la administración (SUNAT y el Tribunal Fiscal) para resolver los recursos impugnatorios en sede administrativa.

El vacío normativo en relación a la consecuencia jurídica frente a la vulneración del plazo razonable en el procedimiento contencioso tributario por causa imputable a la administración ha llevado que los contribuyentes soliciten tutela al órgano jurisdiccional ordinario y constitucional para que se inaplique la regla de aplicación de intereses durante el tiempo en exceso de SUNAT y el Tribunal Fiscal para resolver los recursos impugnatorios planteados por el contribuyente.

En un primer momento, la línea jurisprudencial del supremo intérprete de la Constitución se inclinó por amparar la pretensión de los contribuyentes y declarar la inaplicación de los intereses moratorios durante el tiempo en exceso para resolver los recursos impugnatorios, incluso en el horizonte de tiempo que el legislador no habría previsto dichas consecuencia jurídica en el código tributario; es decir, el Tribunal Constitucional destruyó las reglas del derecho tributario aplicando el principio de razonabilidad.

Sin embargo, actualmente se evidencia un apartamiento de la doctrina jurisprudencial producida por el TC en relación al derecho al plazo razonable en el procedimiento contencioso tributario, estableciéndose que la vía idónea para dilucidar dicha controversia es la demanda contencioso administrativa.

Palabras clave: Derecho al plazo razonable, Procedimiento Contencioso Tributario.

\section{ABSTRACT}

In this article, the researchers intend to analyze the jurisprudence of the Constitutional Court and the Supreme Court of the Republic in relation to the right to a reasonable term and the legal consequence when evidencing the affectation of said right against the property right of taxpayers; as well as the reasonableness of default interest during the excess time that the administration (SUNAT and the Tax Court) took to resolve the appeals in administrative proceedings.

The regulatory vacuum in relation to the legal consequence in the face of the violation of the reasonable term in the contentious tax procedure for reasons attributable to the administration has led taxpayers to request protection from the ordinary and constitutional jurisdictional body so that the rule of application of interests is not applied. during the time in excess of SUNAT and the Tax Court to resolve the appeals filed by the taxpayer.

At first, the jurisprudential line of the supreme interpreter of the Constitution was inclined to support the claim of the taxpayers and declare the non-application of default interest during the time in excess to resolve the appeals, even in the time horizon that the legislator would not have foreseen such legal consequences in the tax code; that is, the Constitutional Court destroyed the rules of tax law by applying the principle of reasonableness.

However, currently there is evidence of a departure from the jurisprudential doctrine produced by the $\mathrm{TC}$ in relation to the right to a reasonable time in the contentious tax procedure, establishing that the ideal way to elucidate said controversy is the administrative contentious lawsuit.

Keywords: Right to a reasonable term, Tax Litigation Procedure.

\section{RESUMO}

Neste artigo, os pesquisadores pretendem analisar a jurisprudência do Tribunal Constitucional e do Supremo Tribunal da República em relação ao direito a prazo razoável e a consequência jurídica ao evidenciar a afetação desse direito contra o direito de propriedade dos contribuintes; bem como a razoabilidade dos juros moratórios durante o excesso de tempo que a administração (SUNAT e Tribunal Fiscal) levou para resolver os recursos em processos administrativos.

$\mathrm{O}$ vácuo normativo em relação à consequência jurídica em face da violação do prazo razoável no processo tributário contencioso por motivos imputáveis à administração tem levado os contribuintes a requererem proteção ao órgão jurisdicional ordinário e constitucional para que a regra de aplicação do art. não incidem juros durante o tempo excedente à SUNAT e ao Tribunal Tributário para resolver os recursos interpostos pelo contribuinte.

Em um primeiro momento, a linha jurisprudencial do intérprete supremo da Constituição se inclinou a amparar a pretensão dos contribuintes e declarar a não aplicação dos juros moratórios durante o prazo excedente para a resolução dos recursos, mesmo no horizonte temporal que o legislador não ter previsto tais consequências legais no código tributário; ou seja, o Tribunal Constitucional destruiu as regras do direito tributário ao aplicar o princípio da razoabilidade.

No entanto, atualmente há indícios de afastamento da doutrina jurisprudencial produzida pelo $\mathrm{TC}$ em relação ao direito ao prazo razoável no processo contencioso tributário, estabelecendo que a forma ideal de elucidar tal controvérsia é o contencioso administrativo.

Palavras-chave: Direito a prazo razoável, Processo Contencioso Tributário. 


\section{Introducción}

En la actualidad se está cuestionando ante el órgano jurisdiccional ordinario y constitucional, la afectación al derecho al plazo razonable dentro del procedimiento contencioso tributario, en los periodos donde no existía una regla establecida por el legislador en el artículo $33^{\circ}$ del TUO del Código Tributario que estableciera como consecuencia jurídica la no aplicación de intereses moratorios durante el tiempo en exceso que se tomó la Administración Tributaria y el Tribunal Fiscal para resolver los recursos de reclamación y apelación respectivamente.

El Tribunal Constitucional como supremo intérprete de la Constitución en las sentencias recaídas en los expedientes 04082-2012-PA/TC, 04532-2013-PA/TC y 002252017-PA/TC, aplicando principios inaplicó la regla contenida en el artículo $33^{\circ}$ del TUO del Código Tributario, al haberse acreditado la vulneración del principio de razonabilidad y el derecho al plazo razonable en sede administrativa, ordenando a la administración tributaria recalcular el monto de la deuda tributaria, sin considerar los intereses moratorios durante el plazo en exceso para resolver los recursos impugnatorios en sede administrativa.

Sin embargo, en reciente jurisprudencia del Tribunal Constitucional, se cambió el razonamiento jurídico en relación al derecho al plazo razonable y se estableció que el amparo no era la vía idónea para resolver la consecuencia jurídica de la afectación al plazo razonable durante el tiempo que el legislador no habría legislado en ese extremo, produciéndose un vacío normativo que debería ser cubierto por la jurisprudencia en aplicación de los principios del derecho, a través de la demanda contencioso administrativo.

En la sentencia recaída en el expediente 00222-2017-PA/TC “Caso Scotiabank SUNAT", fue el primer momento que el supremo intérprete de la Constitución se apartó de su doctrina jurisprudencial no vinculante en relación a la consecuencia jurídica de la afectación del derecho al plazo razonable. Así mismo, se estableció que la demanda contencioso administrativo era la vía idónea para dilucidar la controversia, sustentando su decisión en la doctrina jurisprudencial vinculante publicada en el peruano el 22 de julio de 2015:

La vía ordinaria será "igualmente satisfactoria" a la vía del proceso constitucional de amparo si, en un caso concreto, se demuestra, de manera copulativa, el cumplimiento de los siguientes elementos: i) que la estructura del proceso es idónea para la tutela del 
derecho; ii) que la resolución que se fuera a emitir pueda brindar tutela adecuada; iii) que no existe riesgo de que se produzca irreparabilidad; y iv) que no existe necesidad de una tutela urgente derivada de la relevancia del derecho o de la gravedad de las consecuencias (STC -02383-2013-PA/TC, 2015, fj. 15).

En el caso, SCOTIABANK se demostró que no existía necesidad de tutela urgente, al haberse pagado previamente la deuda cuestionada y la entidad financiera seguía funcionando con total normalidad. Así mismo, se demostró que no existía evidencia material que el daño causado por la aplicación de intereses moratorios fuera del plazo legal para resolver los recursos impugnatorios, pueda devenir en irreparable; por lo tanto, la vía idónea e igualmente satisfactoria para solicitar la inaplicación del artículo $33^{\circ}$, es la demanda contencioso administrativa, debido a que los jueces ordinarios por mandato constitucional, también tienen la facultad de realizar el control difuso de una norma y de evidenciarse la incompatibilidad de dicha norma con los preceptos constitucionales, debe preferirse la constitución y declarar la inaplicación de la norma legal por su incompatibilidad con la norma constitucional.

Por lo tanto, desde una perspectiva objetiva, en abstracto, el proceso contencioso administrativo cuenta con una estructura idónea para tutelar la pretensión del contribuyente en relación a la inaplicación del artículo $33^{\circ}$ del Código Tributario, durante el tiempo en exceso para resolver los recursos impugnatorios por causa imputable a la administración (SUNAT y el Tribunal Fiscal), al realizarse dentro del citado proceso por mandato constitucional, el control de constitucionalidad y legalidad de los actos administrativos producidos en sede administrativa, al ser el control de constitucionalidad de las leyes, una prerrogativa reconocida a todos los órganos jurisdiccionales para declarar la inaplicación de una ley por incompatibilidad con la norma constitucional. En ese orden de ideas, de acuerdo con el razonamiento jurídico del Tribunal Constitucional el Banco Scotiabank debió dilucidar su pretensión llevada a la justicia constitucional, en la vía contenciosa administrativa, al contar esta último con una estructura idónea para tutelar la pretensión de la citada entidad financiera.

Así mismo, desde una perspectiva subjetiva, para que un contribuyente acuda a la justicia constitucional, debe examinarse si es que, la recurrente transita por el proceso contencioso administrativo, se podría generar un daño irreparable y si es que existe una necesidad de tutela urgente derivada de la gravedad de las circunstancias, al ser el amparo una vía residual: como regla general, es el riesgo de irreparabilidad del daño 
iusfundamental causado o por causarse a la persona el que determinará que la demanda de amparo resulte procedente. A Contrario sensu, la alta improbabilidad de que el referido riesgo se encuentre presente determinará su improcedencia, habilitándose el tránsito por las vías procesales ordinarias. Y si bien ello merecerá un análisis caso por caso, en principio, dicho riesgo se manifiesta en la prognosis razonable de que en el futuro inmediato no existirá posibilidad de reponer las cosas al estado anterior a aquel en se produjo la alegada violación o amenaza de violación del derecho fundamental (STC 00906-2009-PA/TC, fj. 9).

Ahora bien, la Corte Suprema de la República en las Casaciones № 6829-2016LIMA y 274432018- Lima, estableció que no corresponde que se computen intereses moratorios por el exceso en el plazo que tienen los órganos administrativos para resolver los recursos de reclamación y apelación, al vulnerar el principio de razonabilidad en el ejercicio de las potestades tributarias, de conformidad con los fundamentos establecidos en la sentencia $\mathrm{N}^{\circ}$ 040-82-2012-PA/TC, cuya aplicación fue confirmada por el Tribunal Constitucional a través de la sentencia $\mathrm{N}^{\circ}$ 04532-2013PA/TC, los cuales resultan plenamente aplicables para la absolución de la controversia suscitada en el presente proceso.

Por lo tanto, sea que la controversia en relación a la inaplicación de intereses moratorios durante el tiempo en exceso para resolver los recursos impugnatorios en sede administrativa, se dilucide en la vía ordinaria o en la vía residual del amparo, corresponde que el órgano jurisdiccional determine a través del control difuso la implicación del artículo $33^{\circ}$ del TUO del Código Tributario, al evidenciarse la vulneración del principio de razonabilidad y el derecho al plazo razonable del contribuyente.

Así mismo, se tiene que aplicar la regla vinculante contenida en el fundamento $15^{\circ}$ de la sentencia recaída en el expediente $\mathrm{N}^{\circ} 02383-2013-\mathrm{PA} / \mathrm{TC}$, para evaluar desde una perspectiva objetiva si existe necesidad de tutela urgente para el contribuyente y desde una perspectiva subjetiva, si el daño pueda devenir en irreparable; de no demostrarse dichos supuestos, la demanda de amparo sería declarada IMPROCEDENTE y se determinaría que la estructura del

procedimiento contencioso administrativo es la idónea para dilucidar la controversia en relación a la irrazonabilidad del cobro de intereses moratorios, al acreditarse la vulneración al plazo razonable por causa imputable a la administración (Sunat o el Tribunal Fiscal). 
En ese orden de ideas, el presente artículo tiene como problema de investigación ¿Cuál es la consecuencia jurídica frente a la vulneración al derecho al plazo razonable en el procedimiento contencioso tributario, durante el tiempo en el que existía un vacío normativo en el artículo $33^{\circ}$ del TUO del Código Tributario en relación a la consecuencia jurídica por el exceso en el plazo para resolver los recursos impugnatorios?

El objetivo de la investigación es determinar la consecuencia jurídica al evidenciarse la afectación al derecho al plazo razonable en el procedimiento contencioso tributario, por causa imputable a la administración (SUNAT o Tribunal Fiscal).

La hipótesis de la investigación es que, al evidenciarse la afectación al derecho al plazo razonable en el procedimiento contencioso tributario por causa imputable a la administración, la consecuencia jurídica debe ser la inaplicación del artículo $33^{\circ}$ del TUO del Código Tributario durante el tiempo en exceso para resolver los recursos impugnatorios en instancia de reclamación y apelación.

Los problemas específicos de la investigación son: a) ¿Cuál es la vía idónea para solicitar la inaplicación del artículo $33^{\circ}$ del TUO del Código Tributario, al evidenciarse la afectación al derecho al plazo razonable en el procedimiento contenciosos tributario? b) ¿Existe la necesidad de desarrollar doctrina jurisprudencial vinculante en relación a la capitalización de intereses moratorios y la inaplicación del artículo $33^{\circ}$ del TUO del Código Tributario al evidenciarse la vulneración al derecho al plazo razonable? c)

Los objetivos específicos de la investigación son: a) determinar cuál es la vía idónea para solicitar la inaplicación del artículo $33^{\circ}$ del TUO del Código Tributario, al evidenciarse la afectación al derecho al plazo razonable en el procedimiento contenciosos tributario. b) Determinar si existe la necesidad de desarrollar doctrina jurisprudencial vinculante en relación a la capitalización de intereses moratorios y la inaplicación del artículo $33^{\circ}$ del TUO del Código Tributario al evidenciarse la vulneración al derecho al plazo razonable.

Las hipótesis específicas de la investigación son: a) la vía idónea para solicitar la inaplicación del artículo $33^{\circ}$ del TUO del Código Tributario, al evidenciarse la afectación al derecho al plazo razonable es el procedimiento contencioso administrativo, sólo en caso de evidenciarse la necesidad de tutela urgente y que el daño pueda devenir en irreparable, se puede activar la justicia constitucional para dilucidar la controversia. b) 
Existe la necesidad de generar seguridad jurídica en relación a la constitucionalidad de la capitalización de intereses moratorios y la inaplicación del artículo $33^{\circ}$ del TUO del Código Tributario al evidenciarse la vulneración al derecho al plazo razonable, por lo que resulta necesario la producción de doctrina jurisprudencial vinculante por parte del Tribunal Constitucional o en su defecto, por parte de la Corte Suprema.

\section{Marco teórico}

En esta parte se realizará un análisis de la jurisprudencia del Tribunal Constitucional en relación al derecho al plazo razonable en materia penal y como dicha doctrina se extiende al procedimiento contencioso tributario y cuáles serían las consecuencias jurídicas al evidenciarse su afectación.

\subsection{El derecho al plazo razonable como contenido implícito del derecho} al debido proceso.

El debido proceso, "de origen anglosajón (due process of law) expresa la potestad de los justiciables de acceder a la tutela judicial efectiva a través del desarrollo de un procedimiento, el cual debe observar los principios y garantías contenidos en los instrumentos internacionales y la Constitución Política del Perú, concluyendo en un fallo justo, razonable y proporcional.

El debido proceso para la doctrina internacional es definido como aquél derecho fundamental que garantiza al ciudadano que su causa sea oída por un tribunal imparcial y a través de un proceso equitativo, derecho al proceso debido que agrupa y se desdobla en un haz de derechos filiales reconocidos a la vez todos ellos como derechos fundamentales y que incluye; entre otros principios y garantías, el derecho a la defensa, el principio de igualdad de armas, el principio de contradicción, el principio de publicidad, el principio de aceleración procesal y el de presunción de inocencia (Bandrés, 1992).

Es pertinente precisar que dentro del haz de derechos o contenidos implícitos que se desprenden del derecho al debido proceso, tenemos el derecho al plazo razonable. El TC ha sostenido en reiterada jurisprudencia que el derecho al plazo razonable es un contenido implícito del derecho al debido proceso. Así mismo, el Tribunal Constitucional ha sostenido que tales contenidos implícitos de los "derechos viejos" no debe ser confundido con los derechos nuevos o no enumerados" entendidos como aquellos derechos no mencionados expresamente en la Constitución del Estado, tales como el 
derecho a la verdad, el derecho al agua potable, el derecho al libre desenvolvimiento de la personalidad, el derecho a la eficacia de las leyes y los actos administrativos entre otros derechos que cuentan con pleno reconocimiento constitucional de conformidad con el artículo $3^{\circ}$ de la Constitución del Estado y del desarrollo de la jurisprudencia nacional y comparada (Pestana, 2009).

Según la sentencia recaída en el Expediente No 00465-2009-PHC/TC, el derecho al plazo razonable tiene reconocimiento expreso en

Tratados de Derecho Internacional de los Derechos Humanos, ratificados por el Perú y que tienen rango constitucional. Este derecho es propiamente una manifestación implícita del derecho al debido proceso y a la tutela judicial efectiva reconocida en la Carta Fundamental (artículo 139 de la Constitución) y, en tal medida, se funda en el respeto a la dignidad de la persona humana (fj. 8).

La Corte Interamericana de Derechos Humanos (en adelante la $\mathrm{CIDH}$ ) ha establecido en su jurisprudencia que no siempre es posible a las autoridades judiciales cumplir con los plazos legalmente establecidos, y que, por lo tanto, ciertos retrasos justificados pueden ser válidos para el menor resolver del caso. Sin embargo, lo que resulta incompatible con las previsiones de la convención, es que se produzcan dilaciones indebidas o arbitrarias, por lo que debe analizarse cada caso en concreto si existen circunstancias que justifican la dilación del proceso, o por el contrario, se trata de un retaso si justificación, por lo tanto, arbitrario.

En ese orden de ideas, la CIDH ha desarrollado en su jurisprudencia los elementos que deben tenerse en cuenta a la hora de valorar la razonabilidad del plazo de un proceso. Los criterios jurisprudenciales para analizar la razonabilidad del plazo de un proceso son: a) la complejidad del asunto, b) la actividad procesal del interesado, c) la conducta de las autoridades judiciales. El principio del derecho al plazo razonable ha sido desarrollado jurisprudencialmente en los procesos penales y se ha establecido que la finalidad de dicho derecho es que los acusados permanezcan largo tiempo bajo acusación y asegurar que esta se decida prontamente.

Por lo expuesto precedentemente, no quepa la menor duda que el derecho al plazo razonable es un derecho fundamental vinculado al derecho al debido proceso, en ese sentido, extrapolando dicho principio al ámbito tributario, se puede colegir que los contribuyentes tienen el derecho fundamental a obtener una decisión administrativa en cualquiera de los procedimientos tributarios contenidos en el libro III del Código 
Tributario, dentro del plazo de ley o en un plazo razonable, con el objetivo de evitar causar un perjuicio irreparable en los contribuyentes.

El Tribunal Constitucional se pronunció por primera vez en relación al derecho al plazo razonable en el procedimiento contencioso tributaria y la consecuencia jurídica al evidenciarse su afectación por causa imputable a la administración:

Estas situaciones han sido evaluadas por este Tribunal Constitucional, concluyendo que el proceso constitucional de amparo es la vía idónea para brindar una adecuada tutela del derecho invocado, basándose en que el riesgo de que la agresión resulte irreparable es inminente y, por lo tanto, exige una tutela de urgencia (STC 04082, 2012, fj. 19).

El supremo intérprete de la Constitución estableció que en el caso de autos se evidenciaba la necesidad de tutela urgente, al determinarse que existía certeza que el daño podría devenir en irreparable, razón por la cual sostuvo que el amparo era la vía idónea para brindar una adecuada tutela al derecho al plazo razonable del recurrente.

El Tribunal Constitucional estableció que el hecho que se haya interpuesto una demanda contencioso administrativa (en adelante DCA), no es causa suficiente para rechazar la demanda de amparo, porque en la DCA se cuestiona la deuda tributaria en relación con el capital y en el amparo se cuestiona deuda tributaria en relación a los intereses moratorios. Así mismo, en la DCA se invoca la correcta interpretación y aplicación de las normas tributarias, en cambio en el amparo se plantea la tutela del derecho de propiedad y de los principios de razonabilidad y proporcionalidad.

En la citada sentencia, el máximo intérprete de la Constitución estableció que es problemático extender la regla de no confiscatoriedad de los tributos establecida en el artículo $74^{\circ}$ de la Constitución a los intereses moratorios (STC, 4082-2012, fj. 43).

Los intereses moratorios, a juicio del tribunal se constituyen como sanciones por el pago extemporáneo del tributo, empero aún las sanciones tributarias deben respetar el principio de razonabilidad reconocido en la jurisprudencia del TC y reconocido en el artículo IV, inciso 1.4 del título preliminar de la Ley 27444, Ley del Procedimiento Administrativo General (STC, 40822012, fj. 46).

A juicio del TC la aplicación de la capitalización de los intereses moratorios es excesiva, pues incrementa la deuda tributaria al punto de quintuplicarla, así mismo, es una imposición unilateral del Estado y permite su aplicación irrestricta y sin restricciones. Sin embargo, el ordenamiento jurídico restringe su aplicación en el derecho privado a la 
voluntad de las partes y bajo ciertos supuestos. En ese orden de ideas, la capitalización de intereses de acuerdo con el fundamento jurídico 55 del expediente $\mathrm{N}^{\circ}$ 404082-2012PA/TC es inconstitucional, al trasgredir el principio de razonabilidad de las sanciones administrativas.

Así mismo, el TC estableció que no puede presumirse la mala fe del contribuyente que ejerció su derecho de contradicción administrativa a través de los recursos establecidos en el código tributario, tampoco puede reprimirse con una sanción el ejercicio legítimo de los derechos constitucionales, máxime si el trámite del procedimiento se extiende más allá del plazo legal por causa imputable a la administración. Por lo tanto, al evidenciarse la vulneración al derecho al plazo razonable y los intereses moratorios lesionan el derecho a recurrir en sede administrativa, así como la razonabilidad de las sanciones administrativas, por esa razones el TC aplicando principios inaplicó la regla contenida en el artículo $33^{\circ}$ del TUO del Código Tributario, siendo el primer antecedente jurisprudencial en relación al derecho al plazo razonable y la consecuencia jurídica frente a su afectación por causa imputable a la administración.

\subsection{El derecho al plazo razonable en el procedimiento contencioso}

\section{tributario}

El derecho al plazo razonable debe entenderse como una manifestación implícita del derecho al debido proceso; así mismo, esta garantía se extiende a los procedimientos administrativos y para determinar si en un procedimiento administrativo se ha producido o no la violación del derecho al plazo razonable se deberán evaluar los siguientes criterios (STC, 04532-

2013, fj, 33).

\subsubsection{La complejidad del asunto}

Aquí se consideran factores tales como la naturaleza de la situación fáctica que es materia de evaluación o fiscalización por la administración (procedimiento administrativo ordinario o sancionador), los alcances de la actividad probatoria para el esclarecimiento de los hechos, la pluralidad de administrados involucrados en el procedimiento, o algún otro elemento que permita concluir, con un alto grado de objetividad, que la dilucidación de un determinado asunto resulta particularmente complicada y difícil (STC, 04532-2013, fj, 33). 


\subsubsection{La actividad o conducta procedimental del administrado}

Se evalúa si su actitud ha sido diligente o ha provocado retrasos o demoras en el procedimiento, por cuanto si la dilación ha sido provocada por él no cabe calificarla de indebida. En ese sentido, habrá que distinguir entre el uso regular de los medios procedimentales que la ley prevé y la actitud obstruccionista o la falta de cooperación del administrado, la cual estaría materializada en la interposición de recursos que, desde su origen y de manera manifiesta se encontraban condenados a la desestimación (STC, 04532-2013, fj, 33).

\subsubsection{La conducta de la administración pública}

Se verifica el grado de celeridad con el que se ha tramitado el procedimiento. Para ello, será preciso examinar las actuaciones u omisiones de los órganos competentes para la tramitación del procedimiento, como por ejemplo: lo que ordinariamente se demora en resolver determinado tipo de procesos; la admisión y/o la actuación de elementos probatorios manifiestamente impertinentes; la reiterada e indebida anulación por parte del ente o tribunal administrativo de segundo grado respecto de las decisiones de la autoridad administrativa de primer grado; la demora en la tramitación y resolución de los medios impugnatorios (STC, 04532-

2013, fj, 33).

\subsubsection{Las consecuencias que la demora produce en la situación jurídica del} interesado

Se evalúa si el paso del tiempo en el procedimiento incide o influye de manera relevante e intensa en la situación jurídica (derechos y deberes) del demandante. Ello con la finalidad de que el procedimiento discurra con más diligencia a fin de que el caso se resuelva en un tiempo breve, si es que éste incide o influye de manera relevante e intensa sobre la situación jurídica del demandante (STC, 04532-2013, fj, 33).

2.3. Inicio y fin del cómputo del plazo razonable del procedimiento contencioso tributario

El TC ha establecido que el cómputo del plazo razonable del proceso debe iniciarse desde el momento en que la persona conoce de la de la atribución o del cargo que les afecta a sus intereses, y culmina con la decisión que resuelve de manera definitiva su situación jurídica o determina sus derechos u obligaciones (Expediente 00295-2012PHC/TC, fj. 5). En el ámbito de los procedimientos administrativos, que el artículo 29 del 
TUO de la Ley de Procedimientos Administrativos General Decreto Supremo 004-2019JUS los define como el "conjunto de actos y diligencias tramitados en las entidades, conducentes a la emisión de un acto administrativo que produzca efectos jurídicos individuales o individualizables sobre intereses, obligaciones o derechos de los administrados". En ese orden de ideas, el procedimiento contencioso tributario en instancia de reclamación inicia con la presentación del expediente de reclamación por parte del contribuyente y concluye con la decisión administrativa de la SUNAT. Por otro lado, el recurso de apelación inicia con la presentación del recurso de apelación del contribuyente y el mismo es elevado por la SUNAT al Tribunal Fiscal y culmina con la decisión administrativa del Tribunal Fiscal, la misma que agota la vía administrativa.

En relación a la finalización del cómputo del plazo, este Tribunal entiende que el término del procedimiento administrativo opera en el momento en que la autoridad administrativa expide la decisión definitiva que resuelve la situación jurídica de la persona en sede administrativa, lo cual incluye a los recursos que se establecen dentro del propio procedimiento administrativo para cuestionar una primera decisión de la autoridad. En ese sentido, este Tribunal advierte que, en el caso de autos, el procedimiento contencioso tributario culminó con la expedición de la Resolución 01853-1-2012 por parte del Tribunal Fiscal con fecha 3 de febrero de 2012 (fojas 50), considerando además que el artículo 153 del TUO del Código Tributario establece que "contra lo resuelto por el Tribunal Fiscal no cabe recurso alguno en la vía administrativa" (STC, 04532-2013, fj, $37)$.

En ese sentido, para el TC el inicio y cómputo del procedimiento contencioso tributario

\subsection{Intereses Moratorios}

A juicio del Tribunal Constitucional los intereses moratorios son sanciones administrativas aplicadas por la administración tributaria al haberse producido la demora en el pago de la deuda tributaria autodeterminada o determinada dentro del procedimiento de fiscalización.

El último párrafo el artículo $1242^{\circ}$ del Código Civil establece que el interés moratorio tiene por finalidad indemnizar la mora en el pago. En ese sentido, el interés moratorio tiene por finalidad indemnizar al acreedor tributario al haberse producido la 
mora en el pago de la deuda tributaria autodeterminada o determinada por la administración tributaria en el procedimiento de fiscalización. Sin embargo, el cobro de intereses moratorios resulta constitucionalmente válido durante el plazo que tiene la administración y el tribunal fiscal para resolver los recursos impugnatorios, a contrario sensu, resulta constitucionalmente inválido el cobro de los intereses moratorios durante el tiempo en exceso para resolver los recursos impugnatorios por causa imputable a la administración.

La finalidad del cobro de intereses moratorios en las deudas tributarias es compensar al acreedor tributario por la demora en el pago; finalidad que resulta legítima en tanto la demora sea imputable al deudor tributario. En el procedimiento contencioso tributario el cobro de intereses durante el plazo legal para resolver los recursos impugnatorios, resulta una restricción legítima y razonable al derecho a recurrir las decisiones administrativas, debido a que el contribuyente pudo prever el cobro de intereses durante el plazo que el legislador otorga a la autoridad administrativa para resolver los recursos impugnatorios.

Sin embargo, durante el exceso en el plazo para resolver los recursos impugnatorios por causa imputable a la administración, no resulta constitucionalmente válido sancionar al contribuyente con el pago de intereses moratorios, pues la demora en el pago de la deuda tributaria no puede ser prevista con certeza por el administrado. Por lo tanto, el cobro de intereses moratorios en el tramo en el que la autoridad administrativa se excedió en el plazo para resolver los recursos impugnatorios resulta contrario al principio de razonabilidad y los preceptos constitucionales. Por lo tanto, los jueces constitucionales y ordinarios al evidenciarse la vulneración al derecho al plazo razonable en los procedimientos contenciosos tributarios, por causa imputable a la administración, deben ordenar la inaplicación de los intereses moratorios durante el tiempo en exceso para resolver los recursos impugnatorios, incluso en los periodos en el que el legislador no estableció dicha consecuencia jurídica.

Así mismo, resulta inconstitucional la aplicación de la regla de capitalización de intereses durante la vigencia de la norma, la inaplicación de dicha regla se puede solicitar en el proceso contencioso administrativo vía control difuso o en su defecto, en el proceso de amparo, al evidenciarse la necesidad de tutela urgente y la existencia de un alto riesgo que la demanda pueda devenir en irreparable. 


\subsection{Antecedentes normativos sobre la inaplicación de intereses moratorios} una vez vencido el plazo legal para resolver los recursos impugnatorios.

Con el artículo $6^{\circ}$ del Decreto Legislativo 981, publicado el 14 de marzo de 2007, se establece la siguiente regla:

La aplicación de los intereses moratorios se suspenderá a partir del vencimiento de los plazos máximos establecidos en el Artículo $142^{\circ}$ del TUO del Código Tributario hasta la emisión de la resolución que culmine el procedimiento de reclamación ante la Administración Tributaria, siempre y cuando el vencimiento del plazo sin que se haya resuelto la reclamación fuera por causa imputable a ésta. La suspensión de intereses no es aplicable a la etapa de apelación ante el Tribunal Fiscal ni durante la tramitación de la demanda contencioso-administrativa.

Por lo tanto, a partir del día siguiente de la publicación en el diario oficial el peruano de la regla contenida en el artículo $6^{\circ}$ del Decreto Legislativo 981, el exceso en el plazo para resolver los recursos de reclamación por parte de SUNAT, se sancionaban con la no aplicación de intereses moratorios durante el tiempo en exceso. Ahora bien, se formula la siguiente pregunta:

¿Resulta razonable la aplicación de intereses moratorios durante el tiempo en exceso para resolver los recursos de reclamación, ante un silencio del legislador en relación a la consecuencia jurídica de la afectación del derecho al plazo razonable? A la luz de la jurisprudencia del TC recaída en los expedientes 04082-2012-PA/TC, 045322013-PA/TC y 00225-2017-PA/TC y la jurisprudencia de la Corte Suprema recaída en las Casaciones $\mathrm{N}^{\circ}$ 6829-2016-LIMA y 27443-2018- Lima, consideramos que NO y el juez ordinario o el juez constitucional debe a través del control difuso disponer la inaplicación retroactiva de la regla contenida en el artículo $6^{\circ}$ del Decreto Legislativo 981, al evidenciarse la vulneración del derecho al plazo razonable y tener este derecho conexión directa con el derecho fundamental al debido proceso establecido en el artículo 139 inciso 3 de la Constitución Política del Perú.

Ahora bien, ¿resulta constitucionalmente válido el tratamiento legislativo diferenciado entre los recursos administrativos de reclamación y apelación? la respuesta es definitivamente NO y se sustenta en el fundamento jurídico 28 de la sentencia recaída en el expediente $\mathrm{N}^{\circ}$ 04532-2013-PA/TC 
Por otro lado, no se advierte una causa objetiva que justifique un tratamiento legislativo diferenciado entre los recursos de reclamación y apelación en lo que respecta a la suspensión en el cobro de intereses moratorios luego de vencido el plazo legal establecido para que la autoridad administrativa resuelva los recursos impugnatorios. Ello es así toda vez que si bien cada uno de ellos es conocido y resuelto por distintas entidades administrativas (Sunat y Tribunal Fiscal, respectivamente), dicho aspecto no resulta determinante para reconocer una naturaleza disímil a estos mecanismos impugnatorios, sino que, por el contrario, en ambos casos nos encontramos ante recursos administrativos que pretenden garantizar el derecho al debido procedimiento en su manifestación de facultad para recurrir las decisiones administrativas. Por lo tanto, la disposición que establece la suspensión en el cobro de intereses moratorios durante el tiempo en exceso que, respecto del plazo legal establecido, tomara la administración tributaria para resolver, resulta aplicable durante la tramitación de ambos recursos (reclamación y apelación).

En el citado expediente, el Tribunal Constitucional realizando el control de constitucionalidad de los actos del legislador tributario determinó que no existía una justificación objetiva para otorgar un tratamiento legislativo diferenciado en relación a la suspensión del cómputo de intereses moratorios durante el exceso en el plazo para resolver los recursos de reclamación y apelación, correspondiendo en ambos casos inaplicar el artículo $33^{\circ}$ del TUO del Código Tributario al evidenciarse la vulneración del derecho al plazo razonable y el principio de razonabilidad, al tratarse de recursos impugnatorios en sede administrativa que buscan garantizar el derecho al debido procedimiento en su haz de la facultad para recurrir las decisiones administrativas.

Así mismo, con el artículo 7 de la Ley 30230, publicada el 11 de julio de 2014, modifica la anterior regla, y reduce el cobro de los intereses moratorios solo al periodo que dure el proceso contencioso administrativo:

La aplicación de los intereses moratorios se suspenderá a partir del vencimiento de los plazos máximos establecidos en los Artículos 142, 150 y 152 hasta la emisión de la resolución que culmine el procedimiento de reclamación ante la Administración Tributaria o de apelación ante el Tribunal Fiscal, siempre y cuando el vencimiento del plazo sin que se haya resuelto la reclamación o apelación fuera por causa imputable a dichos órganos resolutores. La suspensión de intereses no es aplicable durante la tramitación de la demanda contencioso-administrativa. 
Con la publicación de la Ley 30230 se corrigió el error del legislador tributario derivado y a partir del día siguiente de su publicación en el peruano, no procede el cobro de intereses moratorios durante el tiempo en exceso para resolver los recursos impugnatorios en sede administrativa, al no existir fundamento objetivo que ampare un tratamiento legislativo diferenciado. Sin embargo, ¿Qué sucede durante el tiempo que no estaba vigente el artículo $7^{\circ}$ de la Ley 30230? Corresponde que el juez ordinario o constitucional inaplique la regla contenida en el artículo $6^{\circ}$ del Decreto Legislativo 981 y extienda la inaplicación de intereses moratorios durante el tiempo en exceso para resolver los recursos de reclamación a los recursos de apelación, así mismo, dicha regla debe aplicarse incluso al periodo anterior a la publicación del citado decreto legislativo, siempre y cuando se evidencia la vulneración al derecho al plazo razonable por causa imputable a la administración.

Ahora bien, se pretende finalizar el presente artículo formulando la siguiente pregunta ¿Resulta constitucionalmente válido el tratamiento legislativo diferenciado en relación a la consecuencia jurídica al evidenciarse la vulneración al derecho al plazo razonable en el procedimiento contencioso tributario y en el procedimiento contencioso administrativo? El último párrafo del artículo $33^{\circ}$ del TUO del Código Tributario establece como regla que en ningún caso se suspenderá el cómputo de los intereses moratorios durante la tramitación de la demanda contencioso administrativo, dicha regla resulta válida si el proceso judicial dura un tiempo razonable; sin embargo, dicha regla deviene en inconstitucional, en los caso que el proceso judicial demora entre 10 y 12 año, lo que resulta una clara vulneración al derecho al plazo razonable y la consecuencia jurídica debe ser la misma que la establecida en el procedimiento contencioso tributario, debiendo el legislador establecer un plazo razonable para la duración del proceso judicial en la demanda contencioso administrativo.

En caso, de no modificarse esa regla los contribuyentes podrían activar la jurisdicción internacional para buscar un tratamiento legislativo similar, al evidenciarse la vulneración del derecho al plazo razonable en sede judicial, dentro de la demanda contencioso administrativo. Por qué no se puede sancionar sólo la vulneración del derecho al plazo razonable de la Administración Tributaria y el Tribunal Fiscal, dejando exento de consecuencias jurídicas la afectación al derecho al plazo razonable por parte del órgano jurisdiccional. 


\section{Método}

Por el nivel de conocimiento que se adquiere, el presente trabajo de investigación es de tipo descriptivo y documental con un enfoque cualitativo. El estudio descriptivo y documental se direcciona en la conceptualización de diversas teorías y doctrinas jurídicas y el análisis de la doctrina jurisprudencial del supremo intérprete de la Constitución y la Corte Suprema de la República, en relación al derecho al plazo razonable en el procedimiento contencioso tributario materializado en los expedientes 04082-2012PA/TC, 04532-2013-PA/TC y N 00225-2017PA/TC; así como las casaciones $\mathrm{N}^{\circ}$ 68292016-LIMA y 27443-2018- Lima.

Así mismo, se analizó los criterios jurisprudenciales expediente 04532-2013$\mathrm{PA} / \mathrm{TC}$, expediente $\mathrm{N}^{\circ}$ 00222-2017-PA/TC y 02218-2015-PA/TC, expedientes donde el Tribunal.

Constitucional se aparta de su doctrina jurisprudencial en relación a la consecuencia jurídica frente a la afectación al derecho al plazo razonable.

Método Inductivo: Mediante este método se recopiló diversos conceptos teóricos y enfoques jurisprudenciales del Tribunal Constitucional y la Corte Suprema de la República en relación al derecho al plazo razonable en el procedimiento contencioso administrativo y la consecuencia jurídica al evidenciarse su afectación, por causa imputable a la administración (Sunat y el Tribunal Fiscal).

Método Analítico: El estudio realiza el análisis de los impactos en la recaudación, de la decisión judicial de inaplicar los intereses moratorios durante el plazo en exceso que se tomo la administración tributaria y el tribunal fiscal para pronunciarse sobre los recursos de reclamación y apelación presentados por el contribuyente, con especial énfasis al caso de Telefónica del Perú y Sunat recaído en el expediente Nº 00225-2017$\mathrm{PA} / \mathrm{TC}$.

\section{Resultados}

\subsection{Resultado 1}

Del análisis de las sentencias recaídas en el expediente 04082-2012-PA/TC, se puede colegir que el Tribunal Constitucional estableció como doctrina jurisprudencial que la capitalización de intereses moratorios incrementa la deuda tributaria al punto de quintuplicarla; por lo tanto, resulta inconstitucional al trasgredir el principio de razonabilidad de las sanciones administrativas reconocido por la jurisprudencia 
constitucional, según se puede apreciar en la Tabla 1 Incremento de la deuda como consecuencia de la capitalización de intereses.

\begin{tabular}{lccc}
\hline $\begin{array}{l}\text { Resolución que origina } \\
\text { la deuda }\end{array}$ & $\begin{array}{c}\text { Monto original de la } \\
\text { deuda }\end{array}$ & $\begin{array}{c}\text { Monto actualizado de la } \\
\text { deuda }\end{array}$ & $\begin{array}{c}\text { Incremento } \\
\text { Porcentual } \\
\text { Aproximado }\end{array}$ \\
\hline $\begin{array}{l}\text { Resolución de } \\
\begin{array}{l}\text { Determinación 024- } \\
\text { 003- 0008223 }\end{array}\end{array}$ & S/ 9339 & S/ 53920 & $577 \%$ \\
$\begin{array}{l}\text { Resolución de } \\
\text { Determinación 024- }\end{array}$ & S/ 12970 & S/ 59601 & $460 \%$ \\
$\begin{array}{l}\text { 003- 0008224 } \\
\text { Resolución de Multa } \\
\text { 024- 002-0022735 }\end{array}$ & S/ 580 & S/ 3352 & $578 \%$ \\
\hline \multicolumn{1}{c}{ TOTAL } & S/ 22889 & S/ 116873 & $510 \%$ \\
\hline
\end{tabular}

Nota. Extraído de la sentencia del Tribunal Constitucional recaída en el expediente $\mathrm{N}^{\circ} 040822012-\mathrm{PA} / \mathrm{TC}$.

En la tabla se puede apreciar la consecuencia de aplicar la regla de capitalización de intereses en la deuda tributaria, la misma que se aplica de manera restringida en el derecho civil para ciertos supuestos y se aplicaba de manera irrestricta en el derecho tributario, lo que evidencia la trasgresión del principio de razonabilidad, el mismo que se constituye como límite al ejercicio de la potestad tributaria del legislador originario, materializado en el artículo $7^{\circ}$ de la Ley 27038. Por lo tanto, el Tribunal Constitucional determinó la inconstitucionalidad de la regla de capitalización de intereses en materia tributaria y ordenó a SUNAT su inaplicación en el caso en concreto. No obstante, la doctrina jurisprudencial producida por el supremo intérprete de la Constitución ha sido aplicada por la Corte Suprema en la Casación N²7443-2018-Lima.

La Corte Suprema de la República en la Casación N²7443-2018 Lima determinó sobre la base de la doctrina jurisprudencial del supremo intérprete de la Constitución, que resultaría a todas luces incongruente que el ordenamiento restrinja la capitalización de intereses libremente pactada y permita su aplicación irrestricta en el ámbito tributario, donde fue impuesta por el Estado durante solo los siete años antes señalados, agregando la máxima corte de la república que la capitalización de los intereses incorpora a los tributos un concepto que no fue previsto por la norma que estableció los elementos configuradores de la obligación tributaria; modificando, mediante una norma posterior, la determinación del monto del pago que debe realizar el contribuyente. 
Esta modificación, no toma en cuenta ninguno de los criterios técnicos previstos para la formulación del tributo (carácter expreso, capacidad contributiva, no confiscatoriedad, etc.), sino, tan solo, la falta de pago de la prestación tributaria. Por lo tanto, la capitalización de intereses resulta abiertamente constitucional al no tener en cuenta los principios de capacidad contributiva y no confiscatoriedad establecidos en el artículo $74^{\circ}$ de la Constitución.

Del análisis de las sentencias recaídas en los expedientes 04082-2012-PA/TC, 045322013-PA/TC y 00225-2017-PA/TC, se determina que el derecho al plazo razonable es un derecho fundamental vinculado intrínsecamente al derecho al debido proceso contenido en el artículo $139^{\circ}$ inciso 3 de la Constitución y vincula a la administración en relación al deber constitucional y legal de SUNAT y el Tribunal Fiscal de emitir un pronunciamiento sobre los recursos de reclamación y apelación dentro del plazo legalmente establecido o dentro de un plazo razonable, con el propósito de no afectar a través de la imposición de intereses moratorios el derecho fundamental a la propiedad de los contribuyentes.

En los citados expedientes, el supremo intérprete de la Constitución estableció que el amparo era la vía idónea para brindar tutela adecuada al derecho invocado, sustentándose en el riesgo de que la agresión resulte irreparable es inminente y; por lo tanto, exige una tutela de urgencia.

Así mismo, se estableció que en la Demanda Contencioso Administrativa el contribuyente cuestiona la correcta aplicación de la norma procesal y sustancial en materia tributaria al caso en concreto; en cambio, en el amparo lo que se discute es la afectación de los intereses moratorios al derecho de propiedad del contribuyente y la afectación a los principios de razonabilidad y proporcionalidad, los mismos que tienen relevancia constitucional.

En el expediente 04532-2013-PA/TC, el supremo intérprete de la Constitución estableció que no existe justificación constitucional para que el legislador establezca un tratamiento diferenciado en relación a la consecuencia jurídica de la afectación al plazo razonable en sede administrativa, estableciendo que la regla contenida en el artículo $6^{\circ}$ del Decreto Legislativo 981 se debía extender al tiempo en exceso que se tomó el tribunal fiscal para resolver los recursos de apelación.

En el citado expediente el Tribunal Constitucional estableció citando su propia jurisprudencia que las personas jurídicas de derecho privado también pueden ser titulares 
de derechos fundamentales (Expediente 0905-2001-AA/TC, fj. 5). Por lo tanto, también pueden ser objeto de tutela frente a la afectación del derecho al plazo razonable por causa imputable de la administración.

\section{2. $\quad$ Resultado 2}

El Tribunal Constitucional en los expedientes 04082-2012-PA/TC, 04532-2013PA/TC y 00225-2017-PA/TC, mantuvo su línea jurisprudencial en relación a la consecuencia jurídica al evidenciarse la afectación al derecho al plazo razonable. Sin embargo, en la sentencia recaída en el expediente $\mathrm{N}^{\circ}$ 00222-2017-PA/TC (Caso Scotiabank Perú SAA), el supremo intérprete de la Constitución se apartó de su jurisprudencia y declaró IMPROCEDENTE la demanda de amparo, con los votos de la Magistrada ponente Marielena Ledesma Narváez, el magistrado Miranda Canales y el Magistrado Espinoza-Saldaña Barrera. El magistrado Blume Fortini manteniendo su posición jurídica votó por declarar fundada la acción de amparo, pero no se alcanzó los votos para amparar la pretensión de la entidad financiera.

En la citada sentencia, el Tribunal Constitucional motivó su decisión en las reglas vinculantes contenidas en el fundamento 5 del expediente 02383-2013-PA/TC, evidenciándose en el caso Scotiabank desde una perspectiva objetiva que el proceso contencioso administrativo cuenta con una estructura idónea para acoger la pretensión de la no aplicación de los intereses moratorios al evidenciarse la afectación del derecho al plazo razonable, por causa imputable a la administración, debido a que los jueces ordinarios tienen la facultad de realizar el control difuso y por lo tanto, inaplicar una norma al evidenciarse su incompatibilidad con los preceptos normativos contenidos en la Constitución.

Sólo se puede activar la justicia constitucional, cuando exista una necesidad de tutela urgente y el daño puede devenir en irreparable, situaciones que no se evidenciaron en el caso Scotiabank, al haberse pagado la deuda tributaria con los intereses que se cuestionan y no hubo una afectación sustancial al derecho de propiedad de la entidad financiera. Así mismo, se puede activar la justicia constitucional en la medida que no sean aplicables los criterios establecidos en el expediente $\mathrm{N}^{\circ}$ 02383-2013-PA/TC.

Así mismo, desde una perspectiva subjetiva se puede activar la justicia constitucional al evidenciarse el riesgo de irreparabilidad del daño y la necesidad de tutela urgente, situación que se debe analizar en cada caso en concreto. 
En el caso Scotiabank, se evidenció la falta de necesidad de tutela urgente y el Tribunal Constitucional aplicando el criterio jurisprudencial contenido en el expediente 02383-2013PA/TC, debió habilitar el plazo, para que la entidad financiera puede recurrir a la justicia ordinaria para solicitar tutela frente a la afectación del derecho al plazo razonable. Sin embargo, los investigadores consideran que, de una manera arbitraria, por el solo hecho de haber activado prematuramente la justicia constitucional, se le restringió el ejercicio del derecho a la habilitación del plazo para recurrir a la justicia ordinaria.

Las razones por las que se declaró improcedente la demanda de amparo, fueron que el BANCO no interpuso ninguno de los mecanismos establecidos en la ley para cuestionar la dilación a nivel administrativo; es decir, el supremo intérprete de la Constitución sancionó la actitud pasiva del BANCO frente a la demora en la resolución de los recursos impugnatorios. Sin embargo, en los expedientes 04082-2012-PA/TC, 04532-2013-PA/TC y 00225-2017-PA/TC, los demandantes tampoco hicieron uso del silencio administrativo negativo o el recurso de queja para cuestionar la excesiva dilación en la emisión de la decisión administrativa en el recurso de reclamación y apelación.

El Tribunal Constitucional estableció que la suspensión de los intereses moratorios debe estar restringida únicamente para aquellos contribuyentes que, con diligencia, han interpuesto el recurso de queja, cuestionando precisamente el exceso de tiempo del Tribunal Fiscal en emitir su resolución en el plazo legal. Así mismo, la justicia constitucional demanda que, por lo general, las personas o entidades supuestamente afectadas por alguna conducta, sea del poder público o de parte de privados no consientan, en el marco de la actuación de aquellas, alguna posible vulneración de derechos fundamentales; antes bien, la competencia de la justicia constitucional solo podrá ser activada cuando las conductas cuestionadas hubiesen sido debidamente impugnadas al interior del proceso respectivo.

En la sentencia recaída en el expediente $\mathrm{N}^{\circ}$ 04559-2018-AA/TC (Caso Administradora del Comercio SA) el Tribunal Constitucional declaró IMPROCEDENTE la acción de amparo que buscaba encontrar tutela en relación a la afectación al derecho al plazo razonable, para lo cual se hizo uso del voto dirimente de la presidente del Tribunal Constitucional en la sesión de 14 de diciembre de 2021. La particularidad de está sentencia es que los magistrados Ferrero Costa, Blume Fortini y Sardón de Taboada votaron por declarar fundada en parte la demanda, lo que significa que de existir una sesión en el presente ejercicio en el que la causa verse sobre la afectación del derecho al 
plazo razonable, la jurisprudencia del supremo intérprete de la Constitución puede dar una nuevo viraje y ajustarse a la doctrina jurisprudencial desarrollada en los expedientes 04082-2012-PA/TC, 04532-2013-PA/TC y 00225-2017-PA/TC.

En el expediente $\mathrm{N}^{\circ}$ 02218-2015-PA/TC (Caso Pluspetrol) se declaró improcedente la demanda, debido a juicio de 03 magistrados del Tribunal Constitucional, a la sustracción de la materia, al haber pagado Pluspetrol el 02 de octubre de 2015 voluntariamente la totalidad de la deuda incluyendo los intereses moratorios cuya prohibición de cobro se pretendía en la demanda. Sin embargo, los magistrados Ferrero Costa, Blume Fortini y Sardón de Taboada, votaron por declarar fundada la demanda; por lo que se tuvo que hacer uso del voto dirimente de la magistrada presidenta del Tribunal Constitucional, a la fecha de la realización de la sesión del pleno.

\section{Conclusiones}

5.1. Se advierte la existencia de decisiones judiciales contradictorias en relación a la consecuencia jurídica, al evidenciarse la afectación al derecho al plazo razonable en el procedimiento contencioso tributario, lo que evidencia la necesidad de producir doctrina jurisprudencial vinculante en ese extremo, con el propósito de generar seguridad jurídica.

5.2. Se advierte el apartamiento del Tribunal Constitucional respecto de su doctrina jurisprudencial en relación al derecho al plazo razonable en el procedimiento contencioso tributario, contenidos en los expedientes 04082-2012-PA/TC, 04532-2013-PA/TC y 00225-2017PA/TC.

5.3. El Tribunal Constitucional como supremo intérprete de la Constitución, en aplicación de los principios contenidos expresamente o implícitamente en el artículo $74^{\circ}$ de la Constitución, puede destruir las reglas del derecho tributario, garantizando de esta manera la plena vigencia de los derechos fundamentales de los contribuyentes.

5.4. El derecho al plazo razonable constituye una manifestación implícita del derecho al debido proceso contenido en el artículo $139^{\circ}$ inciso 3 de la Constitución y despliega sus efectos a todo tipo de proceso o procedimiento, donde se incluye el procedimiento administrativo tributario.

5.5. El plazo del procedimiento tributario será razonable sólo si comprende un horizonte de tiempo necesario y suficiente para el desarrollo de las actuaciones procesales necesarias que se requieran en cada caso en concreto, así como para el ejercicio de los 
derechos de los contribuyentes, a fin de obtener una decisión definitiva que determine los derechos y obligaciones del contribuyente.

5.6. Para evaluar si en el ámbito del procedimiento contencioso tributario se ha producido la violación del derecho al plazo razonable se deberán evaluar los siguientes criterios: a) La complejidad del asunto, b) la actividad o conducta procedimental del contribuyente, c) la conducta de la autoridad tributaria y del tribunal fiscal y d) las consecuencias jurídicas que la demora produce en la situación jurídica del contribuyente.

5.7. El proceso de amparo resulta una vía idónea para cuestionar la afectación al derecho al plazo razonable de personas naturales y jurídicas, siempre que se evidencia la necesidad de tutela urgente desde una perspectiva subjetiva y desde una perspectiva objetiva, se demuestre que no son aplicables de manera copulativa al caso en concreto, las reglas jurisprudenciales vinculantes contenidas en el fundamento 5 de la sentencia recaída en el expediente 02383-2013-PA/TC.

5.8. En la demanda contencioso administrativa se puede solicitar tutela al órgano jurisdiccional para la inaplicación de la regla de capitalización de intereses y la inaplicación de intereses moratorios durante el tiempo en exceso de la administración para resolver los recursos impugnatorios.

5.9. Corresponde a los jueces ordinarios o constitucionales vía control difuso inaplicar la regla de capitalización de intereses, por ser a juicio del supremo intérprete de la Constitución inconstitucional. Así mismo, corresponde evaluar en cada caso en concreto la razonabilidad de los intereses moratorios computados durante el tiempo en exceso para resolver los recursos impugnatorios, por causa imputable a la administración.

5.10. No existe justificación objetiva para un tratamiento legislativo diferenciado en relación a la suspensión de intereses moratorios en instancia de reclamación y apelación. Por lo tanto, la regla contenida en el artículo 6 del Decreto Legislativo $\mathrm{N}^{\circ} 981$ se debe extender al tiempo en exceso del tribunal fiscal para resolver los recursos de apelación.

5.11. No resulta constitucionalmente válido, el hecho de sancionar al BANCO SCOTIABANK con la no activación del plazo para recurrir a la justicia ordinaria, en relación a la afectación al derecho al plazo razonable y la vulneración del principio de razonabilidad, al haberse determinado por los votos en mayoría un apartamiento de la doctrina jurisprudencial del supremo intérprete de la Constitución y por haber recurrido el contribuyente de manera prematura a la justicia constitucional. 
5.12. Las personas jurídicas también pueden ser objeto de tutela frente a la afectación de sus derechos fundamentales a través de la acción de amparo. Así mismo, también resulta amparable la afectación del derecho al plazo razonable a través del amparo, de evidenciarse la necesidad de tutela urgente y que el daño pueda devenir en irreparable.

5.13. En la vía ordinaria se discute la deuda tributaria en relación a la correcta interpretación de la norma tributaria sustancial y procesal aplicable al caso en concreto; en cambio, en la vía constitucional se discute la afectación de los intereses moratorios aplicados durante el tiempo en exceso para resolver los recursos impugnatorios, en el derecho de propiedad de los contribuyentes; así como, la vulneración de los principios de razonabilidad y proporcionalidad.

5.14. Los intereses moratorios se constituyen en una indemnización pagada por el deudor tributario a favor del fisco, al haberse constituido en mora respecto del pago de la deuda tributaria autodeterminada o determinada en un procedimiento de fiscalización.

5.15. Ningún derecho fundamental es absoluto; por lo tanto, resulta constitucionalmente válido el pago de intereses moratorios en el procedimiento contencioso tributario, durante el plazo legal establecido por el legislador para que SUNAT y el Tribunal Fiscal resuelvan los recursos de reclamación y apelación respectivamente.

5.16. No resulta constitucionalmente válido el cobro de intereses moratorios durante el tiempo en exceso de la administración para resolver los recursos impugnatorios, por causa imputable a ésta. Parafraseando a Ronald Dworkin, la administración no se puede beneficiar de su demora en la resolución de los recursos impugnatorios. Por lo tanto, la regla jurisprudencial de no aplicación de intereses moratorios se debe extender durante el tiempo que el legislador no estableció la consecuencia jurídica frente a la demora en la resolución de los recursos impugnatorios.

\section{REFERENCIAS}

Abad, Samuel. (2009). “Amparo y Residualidad: Los cambios introducidos y su desarrollo jurisprudencial”. Edit. Gaceta Jurídica, Lima-Perú.

Albiñala, César, "La Base Imponible y la Base Liquidable". En la Obra Colectiva: Compendio el Derecho Tributario Español, Ministerio de Haciendo; Madrid, 1979. Anacleto, Víctor. (2008). "Guía de Procedimientos Administrativos y del Proceso Barrios, Raúl. (1988). “Derecho Tributario: Teoría General del Impuesto”. Editora Cultural Cuzco, Lima-Perú. 
Bernales, Enrique (1996). "La Constitución de 1993”. Lima - Perú. Edit. CIEDLA.

Bravo, Jorge. (2003). "Fundamentos de Derecho Tributario". Editora Palestra, LimaPerú.

Caballero Bustamante: “Manual Tributario 2006”. N. C. Perú, Lima-Perú 2006, 524pp.

Chávez Morán, J. O., \& Vásquez Lavalle, M. D. P. (2020). El condenado absuelto y la afectación al plazo razonable.

Constitución Política del Perú de 1993.

Contencioso Administrativo". 4ta. Edición, Edit. GRIJLEY, Lima-Perú.

Declaración de abusividad y sus efectos.

Decreto Supremo 135-99-EF Texto Único Ordenado del Código Tributario.

Dialogo con la jurisprudencia. "Actualidad, Análisis y Crítica Jurisprudencial”. Tomo 1, Julio de 1995.

Dialogo con la jurisprudencia. (1995 - 2005). “Actualidad, Análisis Y Crítica Edición, 1987.

Espitia Sanabria, H. H. (2018). Implicaciones jurídicas del silencio administrativo en el caso del estatuto tributario.

Expediente 00222-2017-PA/TC. (2021, 09 de noviembre). Tribunal Constitucional (Marielena Ledezma). https://tc.gob.pe/jurisprudencia/2021/00222-2017-AA.pdf.

Expediente 00225-2017-PA/TC. (2021, 28 de enero). Tribunal Constitucional (Miranda Canales). https://tc.gob.pe/jurisprudencia/2021/00225-2017-AA.pdf.

Expediente 02218-2015-PA/TC. (2021, 26 de octubre). Tribunal Constitucional (Marielena Ledezma). https://img.lpderecho.pe/wpcontent/uploads/2021/11/Expediente-022182015-PA-TC-LPDerecho.pdf

Expediente 02383-2013-PA/TC. (2015, 12 de abril). Tribunal Constitucional (Urbiola Hani).

Expediente 04082-2012-PA/TC. (2016, 10 de mayo). Tribunal Constitucional (Carlos Ramos Núñez). https://www.tc.gob.pe/jurisprudencia/2016/04082-2012-AA.pdf.

Expediente 04532-2013-PA/TC. (2018, 16 de agosto). Tribunal Constitucional (Carlos Ramos Núñez). https://tc.gob.pe/jurisprudencia/2018/04532-2013-AA.pdf. 
Fernández, César. (2000). "Principio de Seguridad Jurídica en Materia Tributaria". Marcial Pons Ediciones Jurídicas y Sociales, Madrid-España.

Gaceta Jurídica S. A., Lima-Perú.

Gaceta Jurídica, 9na. Edición, Lima-Perú.

Giuliani, Carlos: "Derecho Financiero". Vol. I, Buenos aires-Argentina, Ediciones Desalma, $4^{\mathrm{a}}$

Goldfarb, M. (2018). Procedimiento administrativo y silencio de la administración: Régimen del derecho argentino y español.

Hernández, E. (2016). Estudio sobre los intereses de demora en préstamos hipotecarios:

Herrera Sánchez, L. G. (2020). Investigación suplementaria y plazo razonable. https://www.tc.gob.pe/jurisprudencia/2015/02383-2013-AA.pdf.

Iglesias, César. (2000). “Derecho Tributario: Dogmática General de la Tributación”. Editora

Iriarte Yanicelli, A. A. (2016). Los procedimientos amistosos en el derecho fiscal internacional: Propuesta para Argentina.

Jarach, Dino: "El Hecho Imponible". Buenos Aires-Argentina, Edit. ABELEDO PERROT, 1971.

Jurisprudencial”. Gaceta Jurídica, Lima-Perú.

Legal Express N 64, Año 6, abril 2006. Gaceta Jurídica. Guillermo Andrés Chang Hernández.

López Nina, M. (2021). Vulneración al Plazo Razonable en el Proceso Inmediato.

Morón, Juan. (2011). “Comentarios a la Ley del Procedimiento Administrativo General”.

Núñez Rivas, S. Y. (2014). ¿Cuándo Pagar Intereses Moratorios Tributarios?

Otárola, Fredy (2015) "La Constitución Comentada". Tomo III, 3ra. Edición, Gaceta Jurídica, Lima. -Perú.

Porto, Juan. (2010). La Cobranza Coactiva en la Jurisprudencia del Tribunal Constitucional publicado en "Constitución, Economía y Empresa en el Perú”. UPC, Abril, Lima-Perú.

Rehabilitación Social de Macas. 
Restrepo Saavedra, M. I. (2017). Plazo razonable en investigaciones de violaciones de Derechos

Rodríguez Pacheco, R. S. (2020). Los principios de celeridad y plazo razonable en el Centro de

Salazar Nivin, E. J. (2018). La consecuencia jurídica de la vulneración del derecho al plazo razonable en el Sistema Jurídico Penal Peruano.

Sanabria, Rubén. (1999). "Derecho Tributario e Ilícitos Tributarios”. 4ª Edición, Gráfica Horizonte, Lima-Perú.

Simões Valença de Melo, L. G. (2014). Derecho fundamental a la razonable duración del proceso tributario y vulnerabilidad procesal del contribuyente fernete a la paradojal debilidad de la hacienda pública: Descontruyendo un falso axioma.

Velásquez Meléndez, R. (2013). Tres enfoques constitucionales sobre los intereses moratorios tributarios.

Velasquez, Juan. (1997). "Derecho Tributario Moderno: Introducción al sistema Moderno". Editorial GRIJLEY EIRL, Lima-Perú.

Villegas B. Héctor: “ Curso de Finanzas y Derecho Tributario”. Buenos Aires-Argentina, Ediciones Desalma, 2a Edición. 